\title{
Construindo o aprendizado de forma coletiva: criação de jogos para exploração de conceitos em uma disciplina de IHC
}

\author{
Milene Selbach Silveira \\ Escola Politécnica - Pontifícia Universidade Católica do Rio Grande do Sul (PUCRS) \\ Porto Alegre - RS - Brazil \\ milene.silveiraepucrs.br
}

\begin{abstract}
Methodological alternatives have been discussed to promote a greater engagement of students in the learning process. In this scenario, we report an experience carried out in two editions of an HCI course, involving 45 students in total. The students created their own (digital and non-digital) games to explore specific HCI concepts. We describe the experience and the students' impressions of its impact on their learning process.
\end{abstract}

Resumo. Alternativas metodológicas têm sido discutidas para promover um maior envolvimento dos alunos no processo de aprendizagem. Nesse cenário, relatamos uma experiência realizada em duas edições de uma disciplina de IHC, envolvendo 45 alunos no total. Os alunos criaram seus próprios jogos (digitais e não digitais) para explorar conceitos especificos de IHC. Descrevemos a experiência e as impressões dos alunos sobre o impacto desta em seu processo de aprendizado.

\section{Introdução}

Alternativas à tradicional aula expositiva têm sido propostas, com abordagens como o aprendizado baseado em projetos e em problemas, a sala de aula invertida, a aprendizagem por pares, o uso de jogos e a gamificação. Em comum entre estas diferentes abordagens, encontra-se o foco no protagonismo do aluno, motivando-se este a passar de uma postura passiva para uma postura ativa em relação a seu aprendizado.

Especificamente relacionado ao uso de jogos em sala de aula, foco deste trabalho, no próprio WEI uma série de iniciativas têm sido apresentadas, como abordagens desplugadas com propostas dos jogos de cartas Computasseia [Santos e Figueiredo 2016], para ensino de História da Computação, e ActGame [Silva, Steinmacher e Conte 2017], para ensino da construção de Diagramas de Atividades da UML (Unified Modeling Language), e abordagens digitais, com construção de jogos para apoio ao aprendizado de diferentes tópicos, como gestão de projetos de software [Leite et al. 2015], pensamento computacional [Vahldick et al. 2016] e protocolos RIP (Routing Information Protocol) [Silva 2019], por exemplo.

No trabalho aqui apresentado, diferente dos trabalhos referenciados, que apresentam a produção e/ou utilização de um jogo específico, será descrita a experiência de construção de jogos pelos próprios alunos, para explorar diferentes tópicos relacionados a uma disciplina de pós-graduação stricto sensu relacionada à área de Interação Humano-Computador (IHC). A experiência a ser relatada se deu em duas 
edições da disciplina: em 2019, com construção de jogos “em papel”, e, em 2020, com a construção de jogos que pudessem ser jogados online.

Para apresentar esta experiência, na Seção 2 é detalhado o processo seguido para criação dos jogos, na Seção 3 a experiência em si, na Seção 4 as impressões dos alunos e, na Seção 5, algumas considerações finais e perspectivas de trabalhos futuros.

\section{O Processo de Criação dos Jogos}

A atividade de criação de jogos foi aplicada, pela primeira vez, em duas disciplinas da graduação e em uma da pós-graduação stricto sensu, no primeiro semestre de 2019, sendo focada em jogos de tabuleiro "em papel" [Silveira 2020]. No primeiro semestre de 2020, considerando a necessidade de se trabalhar de forma remota, a mesma atividade foi proposta aos alunos sendo que, desta vez, eles deveriam criar um jogo que pudesse ser jogado de forma online, enfatizando-se que não deveria ser necessário programar o jogo (poderiam, inclusive, fazer "em papel”, se assim o desejassem).

As etapas da atividade foram assim definidas, independentemente de ela ter sido executada de forma presencial ou remota: (1) organização do grupo, (2) criação do jogo, (3) jogada e (4) feedback. Cada uma destas etapas pode ser vista em detalhes na Tabela 1, com destaque para as especificidades de cada período (presencial ou remoto).

Tabela 1. Detalhamento do processo de criação dos jogos.

\begin{tabular}{|c|c|c|c|}
\hline & Etapas & Período presencial & Período remoto \\
\hline \multirow[t]{3}{*}{$\begin{array}{l}\text { Organização } \\
\text { do grupo }\end{array}$} & $\begin{array}{l}\text { Formação dos } \\
\text { grupos }\end{array}$ & Escolha por conveniência & \multirow{2}{*}{$\begin{array}{l}\text { Uso da ferramenta de Escolha } \\
\text { do Moodle pelos alunos para } \\
\text { indicarem o tópico desejado }\end{array}$} \\
\hline & $\begin{array}{l}\text { Distribuição dos } \\
\text { tópicos }\end{array}$ & Distribuição de forma aleatória & \\
\hline & $\begin{array}{l}\text { Distribuição de } \\
\text { elementos de } \\
\text { jogos }\end{array}$ & $\begin{array}{l}\text { Conjunto com } 3 \text { tabuleiros de } \\
\text { papel, } 2 \text { dados, } 5 \text { peões e } 1 \\
\text { ampulheta a cada grupo }\end{array}$ & $\begin{array}{l}\text { Ênfase em não ser necessário } \\
\text { programar o jogo }\end{array}$ \\
\hline \multirow[t]{4}{*}{$\begin{array}{l}\text { Criação do } \\
\text { Jogo }\end{array}$} & $\begin{array}{l}\text { Estudo do } \\
\text { conteúdo }\end{array}$ & \multicolumn{2}{|c|}{$\begin{array}{l}\text { Uso de material de base (slides com notas de aula) e busca de } \\
\text { aprofundamento deste via publicações da área }\end{array}$} \\
\hline & $\begin{array}{l}\text { Definição das } \\
\text { regras }\end{array}$ & \multicolumn{2}{|c|}{ Definição das regras e das instruções sobre como jogar } \\
\hline & $\begin{array}{l}\text { Definição das } \\
\text { atividades }\end{array}$ & \multicolumn{2}{|c|}{$\begin{array}{l}\text { Definição dos desafios, perguntas e respostas, etc, com foco no } \\
\text { aprendizado do conteúdo relacionado }\end{array}$} \\
\hline & $\begin{array}{l}\text { Criação dos } \\
\text { jogos }\end{array}$ & $\begin{array}{l}\text { Customização dos tabuleiros e/ou } \\
\text { criação de novos materiais }\end{array}$ & Construção do jogo \\
\hline \multirow[t]{3}{*}{ Jogada } & Instalação & $\begin{array}{l}\text { Organização da "estação de jogo" } \\
\text { de cada grupo em mesas }\end{array}$ & $\begin{array}{l}\text { Organização em salas do Zoom } \\
(\text { breakout rooms })^{1}\end{array}$ \\
\hline & Jogo & \multicolumn{2}{|c|}{$\begin{array}{l}\text { Um representante de cada grupo fica na "estação" para moderar a } \\
\text { jogada e os demais circulam }\end{array}$} \\
\hline & + Jogo & \multicolumn{2}{|c|}{ A cada 10-15 minutos os alunos trocam de "estação" } \\
\hline Feedback & $\begin{array}{l}\text { Preenchimento } \\
\text { de formulários }\end{array}$ & \multicolumn{2}{|c|}{$\begin{array}{l}\text { Após a realização das atividades, os alunos são convidados a } \\
\text { preencher um formulário de feedback sobre a atividade }\end{array}$} \\
\hline
\end{tabular}

Os alunos têm uma aula (aproximadamente $1 \mathrm{~h} 30 \mathrm{~min}$ ) destinada para realização (em sala de aula - presencial ou remota) das duas primeiras etapas e, então, mais uma semana

\footnotetext{
${ }^{1}$ No período remoto, as aulas foram ministradas via ferramenta Zoom (https://zoom.us/). Nesta ferramenta, é possível separar os participantes em diferentes salas (breakout rooms) durante um mesmo evento (neste caso, em um mesmo período de aula).
} 
para terminar o jogo (período entre aulas). Na aula seguinte, os jogos são utilizados pela turma (etapa 3), e, após esta aula, o formulário de feedback é liberado para ser respondido, extraclasse, por quem quiser, de forma voluntária (etapa 4).

\section{A Experiência em Sala de Aula}

A disciplina em análise é uma disciplina anual, eletiva, oferecida, sempre no primeiro semestre do ano, aos alunos do Programa de Pós-Graduação em Computação. Ela conta com 30 horas-aula ( 2 créditos), tendo um encontro por semana. Em 2019, a disciplina contou com 19 alunos e, em 2020, com 26 alunos. Ela versa sobre tópicos relacionados à avaliação em IHC, iniciando com conceitos básicos, passando por discussão sobre diversos métodos de avaliação e sua aplicação em pesquisas atuais, e culminando na realização de um trabalho no qual os alunos devem utilizar diferentes métodos de avaliação a fim de embasar uma discussão sobre a aplicabilidade dos mesmos. A atividade aqui descrita tem sido realizada na $3^{\text {a }}$ e na $4^{\text {a }}$ semana de aula, discutindo tópicos relacionados a métodos mais tradicionais de avaliação, como, por exemplo: questões éticas em IHC, métodos para extração da opinião de usuários, métodos de inspeção e métodos de observação de uso.

Em ambas as edições da disciplina, a turma foi dividida em 6 grupos. Todos os grupos que trabalharam presencialmente (2019) construíram jogos de tabuleiro, sendo que, para avançar no mesmo, variavam os tipos de desafio: perguntas e respostas, análises de cenários, colaboração entre os participantes, etc. Já na turma que trabalhou remota (2020), 3 grupos criaram jogos e 3 grupos criaram uma atividade em formato de quiz. Exemplos de jogos de ambas as edições podem ser vistos na Figura 1.

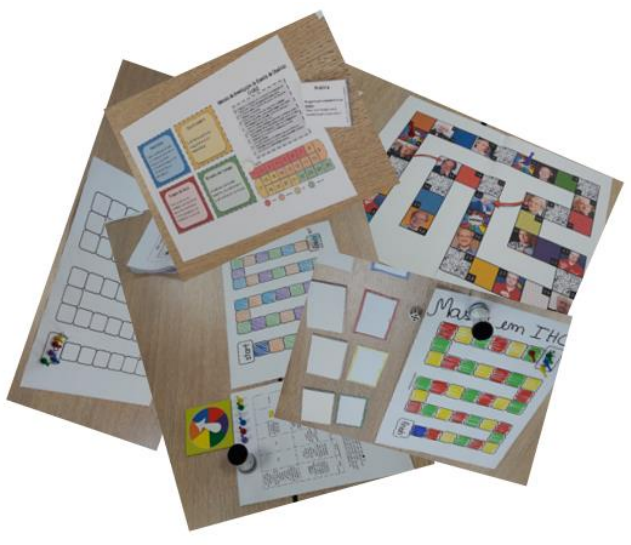

(a) turma presencial

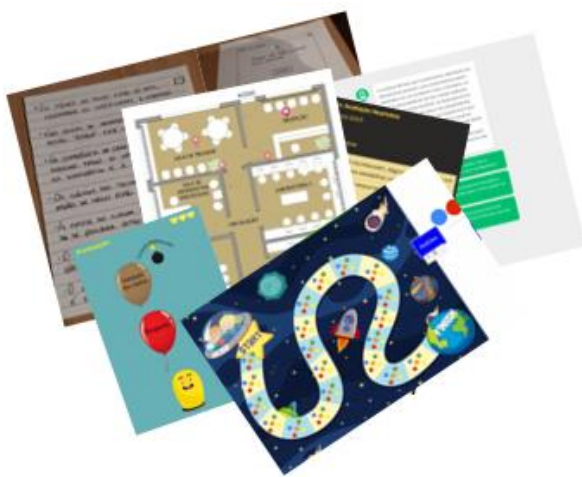

(b) turma remota

Figura 1. Exemplos de jogos desenvolvidos pelos alunos.

Conforme descrito na seção anterior os grupos tiveram uma aula destinada à criação dos jogos, devendo finalizá-los extraclasse antes da aula seguinte. $\mathrm{Na}$ aula destinada à utilização dos jogos criados, a proposta era cada "estação de jogo" estar físicamente separada das demais, para que os alunos pudessem circular pelos jogos, utilizando-os em forma de circuito. Na turma presencial isto funcionou conforme planejado, mas na turma remota, apenas dois jogos eram para ser utilizados em grupo, então os alunos ou "circulavam" entre as duas salas (breakout rooms) que continham estes jogos ou utilizavam algum dos outros jogos de forma individual. 


\section{As Impressões dos Alunos sobre a Experiência}

A fim de verificar as impressões dos alunos sobre a experiência realizada, eles foram convidados a responder um questionário sobre a atividade realizada. Em 2019, 15 dos 19 alunos o responderam e, em 2020, 21 dos 26, totalizando 36 respondentes.

Ao questioná-los sobre as fontes consultadas para o trabalho, 26 (dos 36) usaram como base inicial os slides de aula (sendo que, destes, 5 disseram ter usado apenas estes slides), 14 disseram ter consultado artigos científicos sobre o tema, outros 14 utilizaram livros, 13 citaram consultas a blogs e documentação online e 3 citaram slides de aula encontrados na Internet, demonstrando que a maioria buscou aprofundar o aprendizado sobre o tema.

Já em relação às características dos jogos criados pelos colegas que lhes chamaram a atenção, a Figura 2 apresenta nuvens de palavras relacionadas aos aspectos positivos. Em ambas as turmas, destaca-se a criatividade dos jogos desenvolvidos, mas, na turma presencial, um jogo específico foi muito comentado, por ter promovido a colaboração entre os participantes ("podemos aprender ainda mais com forma colaborativa", "muito interessante a troca de conhecimento entre time para a resolução dos problemas", "jogos que prezavam pelo trabalho em equipe"). Aspectos negativos não foram tão realçados como os positivos, mas questões como a falta de tempo para poder jogar e a necessidade de "ter que estudar" para conseguir jogar (este último, o qual, com certeza deveria ser um requisito) foram citados, de forma negativa, por mais de um aluno. Já na turma que trabalhou remotamente, não houve um jogo que chamasse tanto a atenção, quando da descrição das características, mas quando se questionou qual o jogo mais interessante, na turma presencial, como esperado, 8 dos 15 alunos destacaram o jogo que os participantes deveriam trabalhar de forma colaborativa, e, na turma remota, 18 dos 21 alunos destacaram os jogos de tabuleiro (11 destacaram um dos jogos e 7 o outro), que permitiam que se jogasse em grupos ("possuíam mais interação", "proporcionou interação com os colegas"), ressaltando, novamente, o quanto os alunos prezam a interação durante o processo de aprendizado. Nesta mesma turma (remota), se destacou negativamente o uso excessivo de questionários online (quiz), citado por 7 dos 21 respondentes.

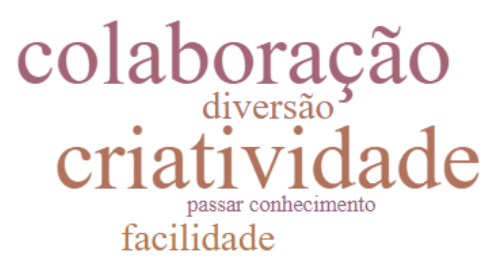

(a) turma presencial

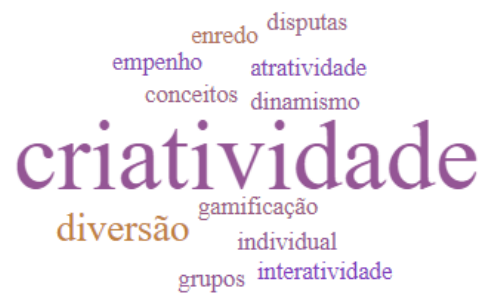

(b) turma remota

Figura 2. Aspectos positivos dos jogos desenvolvidos.

Ao questioná-los sobre o que eles acreditavam que havia lhes ajudado a compreender melhor o conteúdo trabalhado, se a criação ou a utilização dos jogos, 23 (dos 36 alunos) citaram a criação, 5 a utilização e os demais citaram ambas. A criação teve destaque por ser necessário entender o conteúdo para se conseguir criar uma boa dinâmica de jogo e para melhor trabalhar este conteúdo com os colegas. Por fim, ao 
serem questionados se este tipo de atividade favorece o aprendizado, os alunos foram unânimes em dizer que sim; destes, 2 alunos responderam "sim e não", sendo que o não era referente a como alguns dos jogos haviam sido criados.

\section{Considerações Finais}

Lim (2008) destaca a importância de o aluno se encarregar de seu próprio aprendizado, em experiências conjuntas com seus professores e colegas, para um maior envolvimento deste em seu processo de aprendizado. A experiência aqui detalhada corrobora com esta ideia, mostrando como atividades de criação e colaboração podem apoiar esse processo, não apenas ajudando na compreensão de conceitos, mas, também, ajudando no desenvolvimento de diferentes habilidades, como capacidade de trabalhar em equipe, comunicação verbal e escrita, gerenciamento de tempo e resolução de problemas, por exemplo.

A atividade aqui descrita foi aplicada à área de IHC, mas pode ser facilmente reproduzida em outros contextos de Computação (e, mesmo, de outras áreas). Como próximos passos, pretende-se seguir compartilhando este tipo de experiência com outros professores a fim de se obter dados que possam ser utilizados tanto para refiná-la quanto para se (re)pensar outras abordagens metodológicas que ajudem a promover $o$ protagonismo do aluno durante o processo de ensino e de aprendizagem.

\section{Referências Bibliográficas}

Leite, D.; Delfino, S.; Mélo, C.; Medeiros, Á.; de Andrade, H. (2015) Gsprojects Ambiente para Simulação da Gestão de Projetos de Software. In: Anais do XXIII Workshop sobre Educação em Computação.

Lim, C.P. (2008) Spirit of the game: Empowering students as designers in schools? British Journal of Educational Technology, 39: 996-1003.

Santos, J.C.O.; Figueiredo, K. S (2016) Computasseia: um Jogo para o Ensino de História da Computação. In: Anais do XXIV Workshop sobre Educação em Computação. 31-40.

Silva, H. (2019) RIPChallenge: Um Jogo Sério para Auxílio ao Aprendizado do Protocolo RIP. In: Anais do XXVII Workshop sobre Educação em Computação. 503512.

Silva, W.; Steinmacher, I.; Conte, T. (2017) Apoiando o Ensino de Diagrama de Atividades através de um jogo educacional. In: Anais do XXV Workshop sobre Educação em Computação.

Silveira, M.S. (2020) Exploring Creativity and Learning through the Construction of (Non-Digital) Board Games in HCI Courses. In: Proceedings of 2020 ACM Conference on Innovation and Technology in Computer Science Education. 246-251.

Vahldick, A.; Mendes, A.; Marcelino, M.; Farah, P. (2016) Pensamento Computacional Praticado com um Jogo Casual Sério no Ensino Superior. In: Anais do XXIV Workshop sobre Educação em Computação. 308-317. 